\title{
Formation of Functional Nanobiocatalysts with A Novel and Encouraging Immobilization Approach and Their Versatile Bioanalytical Applications
}

\author{
Didar Tasdemir ${ }^{1}$, Cagla Celik ${ }^{1}$, Ayse Demirbas ${ }^{2}$, Ahmet Katı ${ }^{3}$, Osman Tolga Gul ${ }^{4}$, Behzat Çimen ${ }^{5}$ and \\ Ismail Ocsoy*1 \\ ${ }^{1}$ Department of Analytical Chemistry, Faculty of Pharmacy, Erciyes University, Kayseri, 38039, Turkey \\ ${ }^{2}$ Faculty of Fisheries and Aquatic Sciences, Recep Tayyip Erdogan University, Rize, 53100, Turkey \\ ${ }^{3}$ Department of Detergent and Chemical Technologies, Hayat Kimya Research and Development Center, \\ Kocaeli, 41250, Turkey \\ ${ }^{4}$ Department of Physics, Faculty of Science and Arts, Gazi University, Ankara, 06900, Turkey \\ ${ }^{5}$ Department of Biochemistry, Faculty of Pharmacy, Erciyes University, Kayseri, 38039, Turkey
}

\# Corresponding Author: ismailocsoy@erciyes.edu.tr

\begin{abstract}
A recent breakthrough in preparation of immobilized enzyme based biocatalysts achieving highly enhanced enzymatic activities and stabilities has become a great alternative to conventional immobilization techniques. The functional hybrid nanobiocatalysts (FHNs) fabricated in this immobilization composed of organic components (amino acid, peptide, protein, enzyme and plant extract) and inorganic components (various metal ions) give flowerlike morphology with narrow size distribution and porous structure. The enzyme incorporated FHNs exhibite greatly enhanced catalytic activities and stabilities compared to free and conventionally immobilized enzymes under various experimental conditions. In addition to that, the FHNs consisting of other organic components act as Fenton-like reagents and show peroxidase-like activity owing to presence of metal ions and porous structure in the FHNs. This report basically focuses on preparation, characterization, and bioanalytical applications of the FHNs and explain mechanism of the FHNs formation and thier enhanced activities and stabilities.
\end{abstract}


1. Introduction

Enzymes have been considered as versatile biological tool for the synthesis, cleavage and conversion of the compounds in biological and industrial systems. The reasons for their extensive uses in free form are their intrinsic high catalytic activity, substrate selectivity, low toxicity and water solubility. They effectively and selectively catalyze the substrates with high reaction speed in the opimal experimental conditions (typically at room temperature, atmospheric pressure and around neutral $\mathrm{pH}$ values). While enzymes may react with one or a few substrates due to their substrate specificity, they may catalyze whole substrate or their certain parts [1-3]. However despite these advantages, short live time in aqueous and organic medium, quick loss of activity (at high temperatures, at acidic or basic pHs and high salt concentration), and lack of separation from reaction medium and reusability are potential disadvantages of free enzymes and which make them quite expensive and highly suppress their use in diverse range of applications [4-7].

To overcome those limitations, conjugation of enzymes to a supports called "enzyme immobilization" was developed. It is worthy to mention that enzymes in natural systems exist as immobilized enzymes because they are usually bound to the cell membrane and show high stability and activity. For this reason, researchers have aimed to simultaneously enhance the stability and activity of enzymes by immobilizing them to various materials with different immobilization methods. However, the realities did no math with their aims. While enzymes in free form exhibit high acitvities and low stabilities as aforementioned above, immobilized enzyme usually have showed lower activities and higher stabilities compared to free ones. The 3 major effects; 1 ) the mass transfer limitations, 2) restriction of enzyme mobility and 3) conformational changes of enzyme can be considered as potential factors for the loss of catalytic activities [8-10]. There is only very few reports showed the enhanced catalytic activities after immobilization. For instance, Ackerman and co-wrokers demonstrated that the immobilized organophosphorus hydrolase enzyme into mesoporous silica nanomaterials exhibited increased activity (200\% activity) compared to free from of corresponding enzyme [11]. 


\section{Conventional Immobilization Techniques}

Up to now, many different enzymes have been immobilized on various supports such as glass, membrane, polymer, gel beads, sol-gel supports, porous silicon matrix, porous monolithic and nano sized materials with mostly used four different conventional immobilization methods including adsoption, covalent binding, entrapment andcross-linking [12-16]. The water solubility and/or insolubility, biocompatibility, surface functionality and size and morphology are ciritcal features to choose the supports for immobilization. Using various external supports generally enabled us to arrange amount of immobilized enzymes and to reuse them $[2,17]$. Despite all these developments, most of immobilized enzymes have showed great stabilities towards environmental conditions (temprature, $\mathrm{pH}$ values etc.), but they inevitably have exhibited reduction in thier catalytic activities owing to following effects: 1) resriction in mass transfer between enzyme and substrate, 2) limited mobility and 3) unfavorable conformation compared to free enzymes $[18,19]$.

For instance, Corderio et al., Kumar et al., and Singh et al., succesfully immobilized $\alpha$-amylase to the reactive polymer, amonolithic silica nanohybrid and PAni-PVA materials, respectively. Although immobilzied $\alpha$-amylase were highly stable against reaction temperature and some metal ions used as inhibitors, immobilization allows us to reperatedly use it and showed lower activitiy compared to its free form [20-22]. Moreover, in order to strengthen bonds between enzymes and the supports, the crosslinking agents played a crucial role to provide covalent attachment $[2,23-36]$.

Additionally, decreasing materials size to nano in enzyme immobilization has become much pronounced owing to much higher surface to volume ratio compared to micro sized materials. The nanomaterials (NMs) effectively increase the number of loading enzymes in their surface and local enzyme concentration, both of which may improve enzyme stability and activity. Several, plasmonic, magnetic metal and metal oxide and polymeric $\mathrm{NMs}\left(\mathrm{Fe}_{3} \mathrm{O}_{4} \mathrm{NMs}, \mathrm{CdTe}\right.$ dots, $\mathrm{ZnO}, \mathrm{Au}$ and $\mathrm{SiO}_{2} \mathrm{NMs}$, etc.,) were efficiently used as external supports for enzyme immobilization. While significantly more enzyme were immobilized enzymes on per volume unit of the NMs and higher mechanical and thermal stability were observed, the increase in activity has still remained limited compared to the free enzyme dissolved in solution [28-36]. 
3. Functional Nanobiocatalysts Formation (FHNs)

A while ago, an encouraging an method in enzyme immobilization accidently discovered by Zare and coworkers demonstrate that immobilized enzymes have showed simultaneously and greatly enhanced activities and stabilities compared to free and conventionally immobilized enzymes [37]. They reported the synthesis of organicinorganic nanostructure in a flower-shape using protein/enzyme as organic part and $\mathrm{Cu}$ (II) ions as inorganic part in phophate buffred saline (PBS) solution. The main principle for formation of nanoflower relies on following efects: 1) $\mathrm{Cu}$ (II) ions react with phosphate to create primary copper phosphate naocomplexes $\left(\mathrm{Cu}_{3}\left(\mathrm{PO}_{4}\right)_{2}\right)$ in nucleation step, 2$)$ the amide groups in the protein backbone prefrentially bind to $\mathrm{CU}$ (II) ions in $\mathrm{Cu}_{3}\left(\mathrm{PO}_{4}\right)_{2}$ nanocomplexes to form flower petals in growth step and 3) the petals adhere each other to produce nanoflower in final completion step. Proposed mechanism of organic-inorganic nanoflower formation was illusrated in Figure 1.

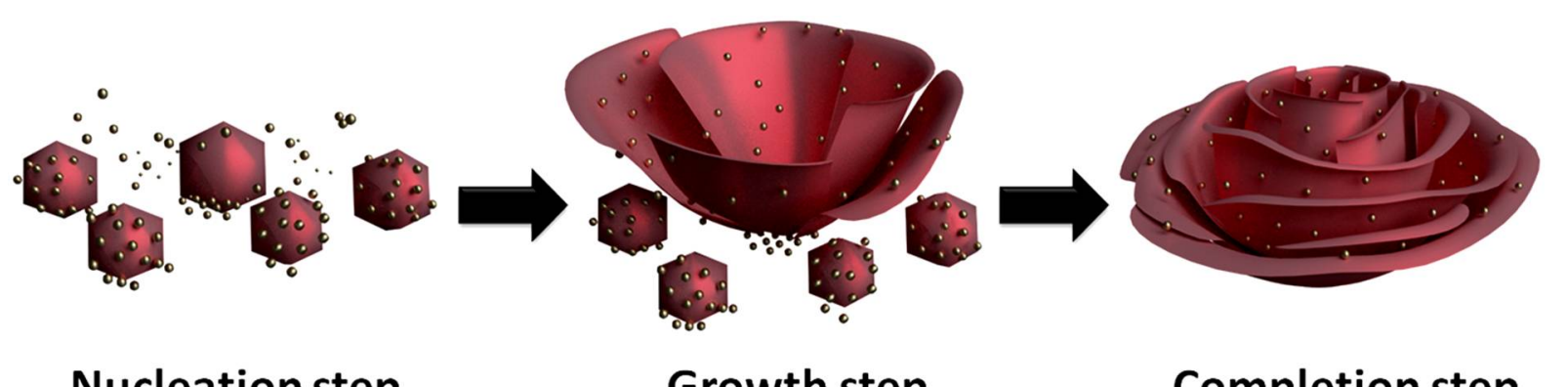

Nucleation step

Growth step

Completion step

Figure 1. Production of organic component-incorporated nanoflowers with potential mechanism incdluing three successive steps (nucleation, growth and completion).

\subsection{Single Enzyme Incorporated FHNs}

The nanoflowers exhibit significant enhancement in activity and stability compared to free and conventionally immobilized enzymes. The enhanced activity of nanoflowers can be explained with these effects: 1 ) porous stctures and high surface area of nanoflowers, 2) facilitation of mass transfer, 3) synergistic effects occured between enzyme molecules and 
enzyme-metal ions, 4) high local enzyme concentration and 5) favorable conformation of enzyme molecules in nanoflowers.

Many researchers inspired from the nanoflower concept have developed various enzymeinorganic hybrid nanoflowers for variety of applications. In terms of inorganic component, some metal ions including copper (II), iron (II), calcium have been used as inorganic part of nanoflower [38-47]. A wide range of enzymes containing commercially available and isolated from the plants, $\operatorname{HRP}[38,39,40], \operatorname{SBP}[41]$, alfa-chymotypsin [42], laccase [43, 48], urease [44], lactoperoxidase [45], lipase [46], Turkish black radish peroxidase [47], have been successfully incorporated into the nanoflower synthesis. The nanoflowers have provided variety of applications such as, calorimetric sensors to detect $\mathrm{H}_{2} \mathrm{O}_{2}$, phenol [38], dopamine [39, 45], epinephrine $[43,45]$, dye decolorization $[47,48]$, and protein digestion [42].

\subsection{Multi- Enzyme Incorporated FHNs}

One of the most exciting advances in nanomaterial synthesis is to produce hybrid nanomaterials (HNMs). The HNMs consisting of several individual domains (components) have usually exhibited enhanced physical and chemical properties or multifunctionalities in one platform compared to single-component NMs. The development of HNMs also has opened up numerous new opportunities to use HNMs in different scientific and technical areas $[49,50]$.

Recently, as example of multifunctionalities of HNMs, several groups have reported synthesis and applications of multi-enzyme containing organic-inorganic hybrid nanoflowers. Having multi-enzyme in a single nanoflower allows simultaneous or stepwise catalysis of cascade reactions in one pot. So, a production of one enzymatic reaction by an enzyme on the nanoflower is catalyzed by the adjacent enzyme on the same nanoflower to perform another reaction. The close proximity between co-enzyme on the nanoflower induces cascade reactions to occur rapidly in a short time as well as reduces diffusion and decomposition of the product of one of the adjacent enzymes which then will be catalyzed by the other enzyme. For example, Sun et al. reported the synthesis of glucose oxidase (GOx)-horseradish peroxidase (HRP) organic-inorganic hybrid nanoflowers and its calorimetric sensor application for glucose detection [51] as shwon in Figure 2. 

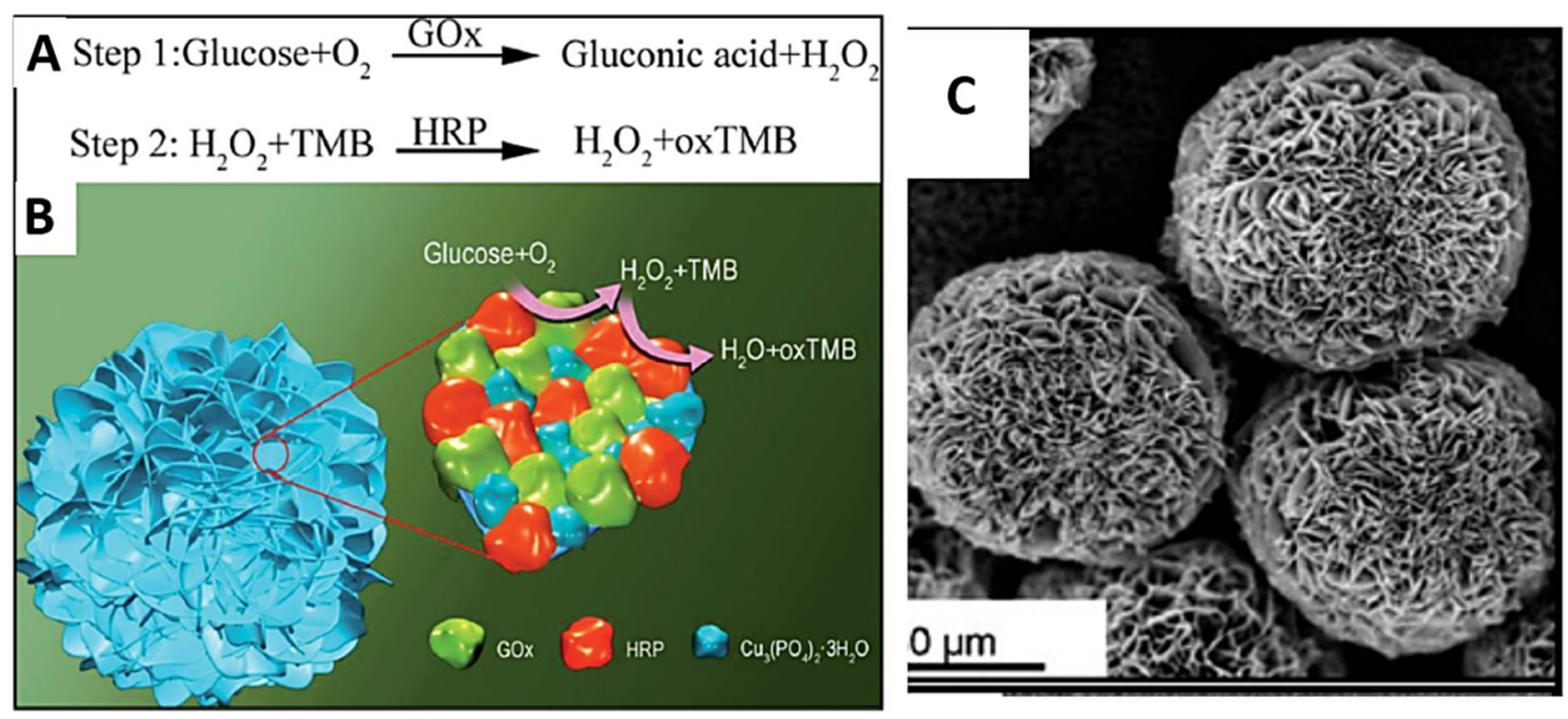

Figure 2. A) Proposed mechanism of glucose detection using a two-step enzymatic reaction in one pot. B) The mechanistic illustration of glucose detection with GOx\&HRP and-Cu (II) incorporated nanoflowers. C) SEM images of GOx\&HRP nanoflowers.

In the synthesized nanoflower, $\mathrm{H}_{2} \mathrm{O}_{2}$, produced by oxidation of glucose by $\mathrm{GOx}$, is catalyzed by HRP to oxidize the $3,3^{\prime}, 5,5^{\prime}$-tetramethylbenzidine, resulting a color change. The performance of GOx-HRP organic-inorganic hybrid nanoflowers in glucose detection was about 4-fold higher than that of the free enzymes and nanoflowers consisting of only GOx or HRP. Glucose detection with GOx-HRP organic-inorganic hybrid nanoflowers deposited microfluidic paperbased analytic device ( $\mu$ PAD) were also developed by Zhu et al. [52]. Ye synthesized concanavalin A (Con A)-invertase organic-inorganic hybrid nanoflowers with calcium ions as inorganic part rather than cooper (II) ions [53]. Thanks to E. coli O157:H7 recognition of Con A and hydrolysis of sucrose to glucose by invertase, they succeeded point-of-care detection of E. coli $\mathrm{O} 157: \mathrm{H} 7$ from milk by measuring glucose amount. Same group also made very similar detection of food pathogen by synthesizing Con A- GOx organic-inorganic hybrid nanoflowers [54]. They, this time, used GOx as signal amplification unit to convert glucose to gluconic acid resulting $\mathrm{pH}$ decrease which can be measured by portable $\mathrm{pH}$ meter. Another calorimetric nanosensor application of multi-enzyme containing organic-inorganic hybrid nanoflowers was designed with streptavidin (SA)- HRP dual enzyme by Liu et al. [55]. The designed nanoflower was able to detect alpha-fetoprotein (AFP) with better sensitivity than commercial enzymelinked immunosorbent assay (ELISA) kits. 


\subsection{Other Organic Component Incorporated FHNs}

The potential mechanism for the formation of protein-inorganic FHNs relies on coordination reaction between the accessible amide groups in the protein/enzyme backbone and $\mathrm{Cu}$ (II) ions in PBS solution. In addition to that, very recent development proved that not only $\mathrm{Cu}-\mathrm{N}$ bond but also $\mathrm{Cu}-\mathrm{O}$ bond can be driving forces in the FHN formation [56-58]. For instance, $\mathrm{Wu}$ et al. used 20 natural amino acids as organic component and $\mathrm{Cu}$ (II) ion as inorganic component to form FHNs. The study demonstrated that $\mathrm{CU}$ (II) ion both react with amine and carboxyl group and the FHNs consist of $\mathrm{Cu}-\mathrm{N}$ and $\mathrm{Cu}-\mathrm{O}$ bonds [56]. Synthesis of amino acids (AAs) based FHNs and thier time dependent SEM images were presented in Figure 3.

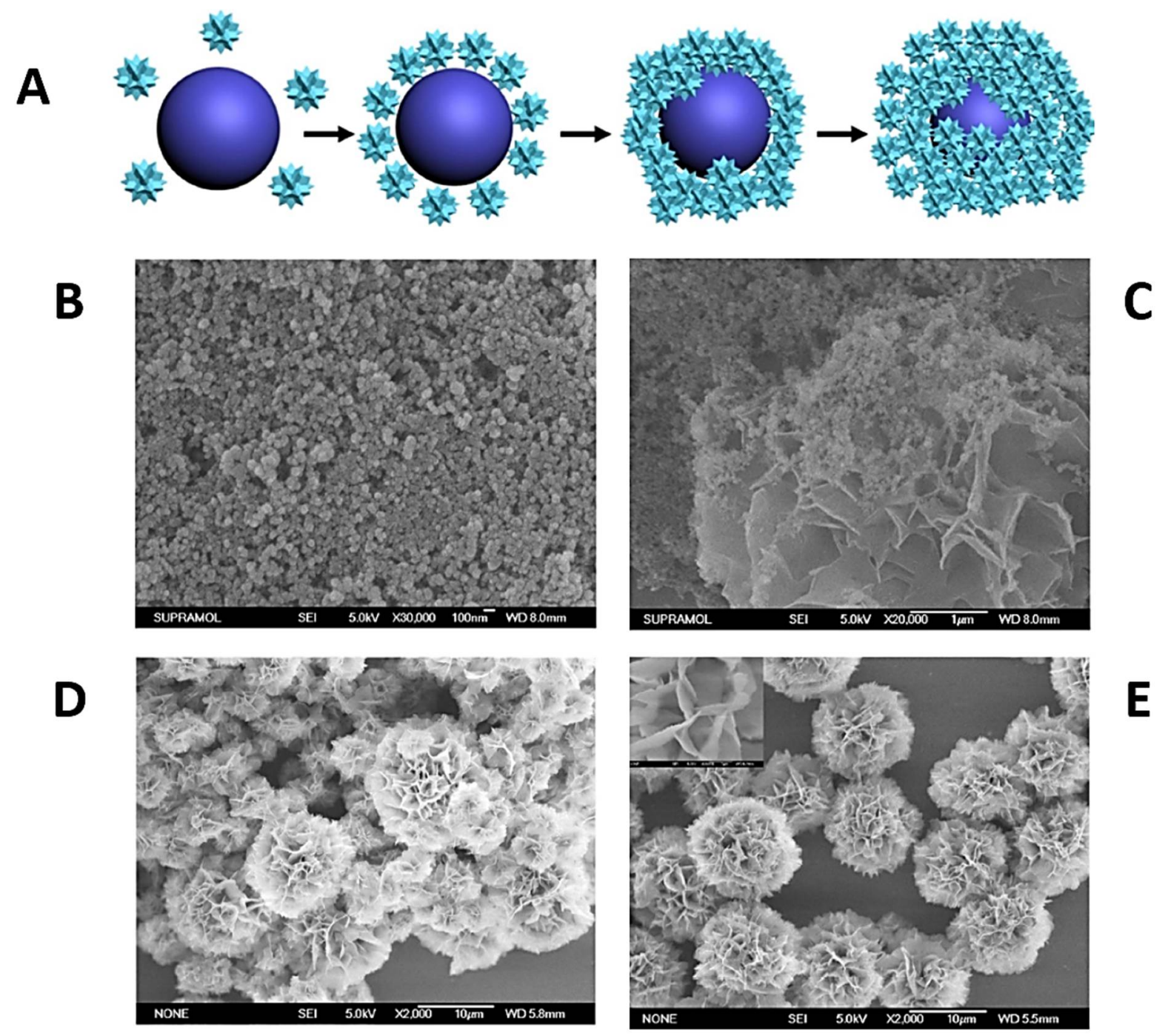


Figure 3. A) The potential mechanism of AAs-FHN formation. Time dependent formation of FHNs in B) 0 hour, C) 0.5 hour, D) 2 hour and E) 24 hours.

Recently, various plant extracts and their active components have been commonly utilized as reducing and capping agents for syntjesis of metallic nanomaterials. Plant extracts have several advantages over other chemical agents in nanomaterials synthesis owing to the following factors: 1) they are quite cost effective, 2) they are easily reachable, 3) lack of contamination risk and 4) no expertise required to work with them.

Ildiz et al., and Baldemir et al., benefited from nanoflower concept and reported, for the first time, synthesis of the FHNs using whole plant extracts and standart molecules acting as organic components [57-59]. Ildız and coworker used Viburnum opulus (VO) extract to form guelder rose like morphology called "nanosnowball" (NSBs) and investigated how concentraiton of VO extract influence the formation of NSBs. They demonstrated how the NSBs behaved like peroxidase enzyme througth Fenton-like reaction mechanism towards guaiacol used as model substrate. The study also reported that the NSBs showed much effective antimicrobial activities against some bacterial pathogens, such as Escherichia coli, Salmonella typhi, Enterococcus faecium, Enterococcus faecalis, Bacillus, Staphylococcus aureus compared to free VO extract. Morphology and peroksidase like activity of the NSBs were showe in Figure 4.
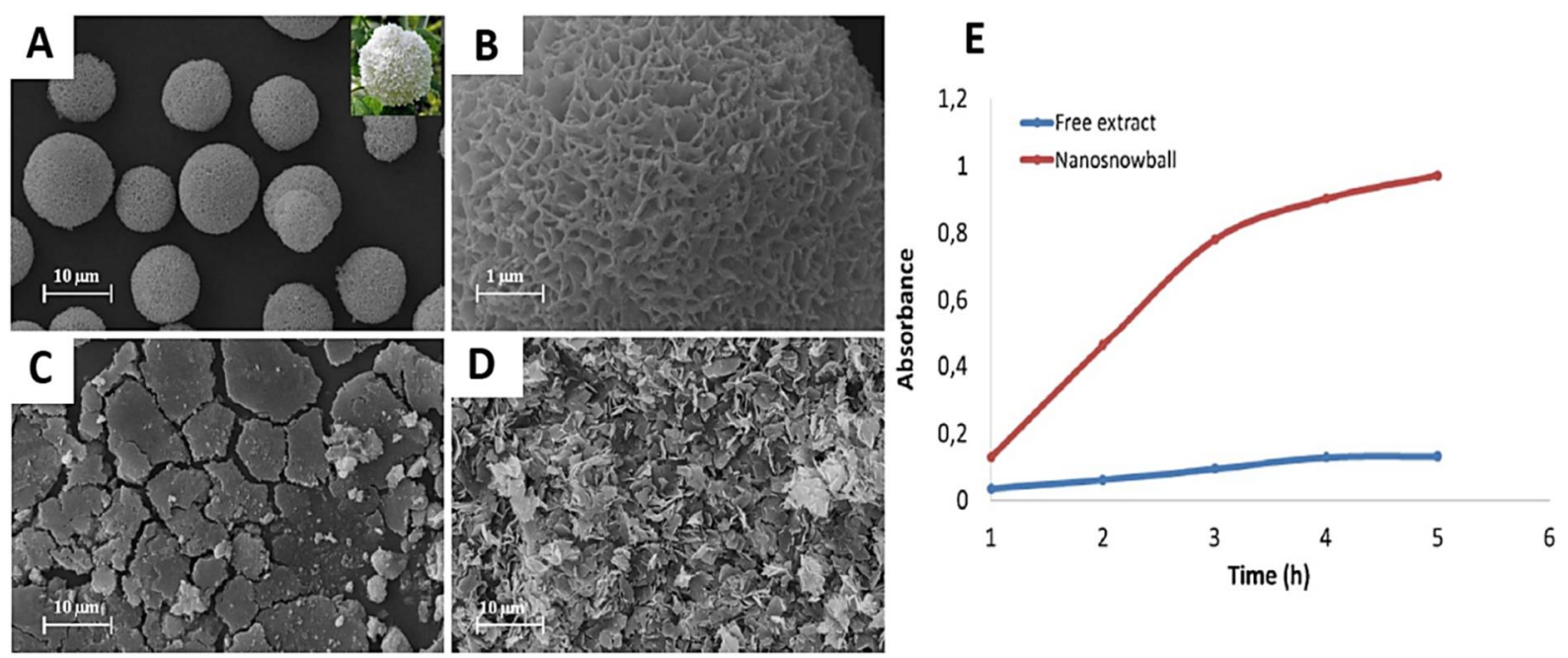

Figure 4. A) SEM image of NSBs synthesized using $0.1 \mathrm{mg} / \mathrm{mL}^{-1} \mathrm{VO}$ extrac. Inlet: photograph of natural VO flower, B) the high resolution image of (A), C) the NSBs formation was not observed 
when $0.5 \mathrm{mg} / \mathrm{mL}^{-1}$ VO extract used. D SEM image of copper phosphate nanocrystals without VO extract. E) Catalytic activity of free VO extract (blue line) and the NSBs (red line).

In terms of peroxidase like activity, the $\mathrm{Cu}$ (II) integrated the FHNs act as Fenton reagent and exhibit peroxidase type activity in the presence of hydrogen peroxide $\left(\mathrm{H}_{2} \mathrm{O}_{2}\right)$ due to intrinsic property of copper compounds. The mechanism of fenton-like reaction as shown in Figure 5 presents that $\mathrm{Cu}$ (II) ions in the structure of FHN react with hydrogen peroxide to form $\mathrm{Cu}(\mathrm{I})$ ions. The reaction of $\mathrm{Cu}(\mathrm{I})$ with $\mathrm{H}_{2} \mathrm{O}_{2}$ results in a highly reactive hydroxyl radical. This free hydroxyl radical initiates the oxidation of the substrate and the reaction proceeds through this mechanism. The peroxidase-like activities of the FHNs are significantly increased by increasing the concentration of $\mathrm{H}_{2} \mathrm{O}_{2}$ and catalyst to the optimal point.

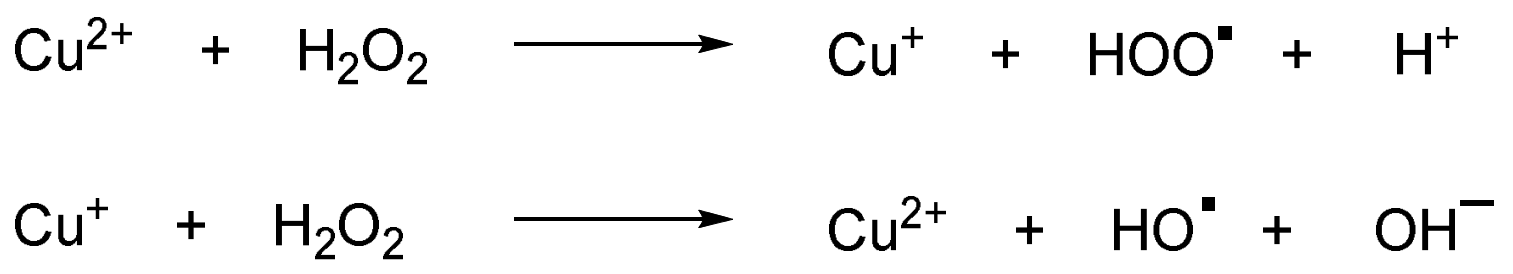

Figure 5. Fenton reaction mechanism

As an other example, Baldemir and coworkers, extended study on plant extract incorporated FHNs. They reported Camellia sinensis (L.) Kuntze extractsi its main components and Laurocerausus officinalis Roemer extracts-CU (II) assembled nanolfowers and showed thier antimicrobial and antiparasitic properties $[58,59]$. Interesting results were obained that while the green tea (GT) extract (extracted in ethanol) and catechin produce the FHNs with very similar morpholoy, green tea (GT) extract (extracted in water) and caffeine based the FHNs have also quite similar shape an size. It can conclude that main components of GT extracted in ethanol and water can be catechin and caffeine molecules, respectively.

\section{Conclusion and future perspectives}

The nanoflower concept has offered unique opportunities to simultaneously increase the activity and stability of enzymes. When looking back and comparing the actvities and stabilities 
of free and conventionally immobilized enzymes, it is understood how discovery of the FHNs preparation has made an enormous impact on "enzyme immobilizaiton stduies". With this recent development, the FHNs make enzyme reusable, efficient and more economical esepcailly for lareg scale use. In stead of using singl enzyme FHNs, combination of two enzymes results in new FHNs with new functionalities like cascade reaction. Beyond the discovery of enzyme based FHNs, researchers extented tyeps of organic part of the FHNs using plant extract and/or standart molecules and investigate thier role in formation of FHNs and thier utilization in many different scientific and industrial fields. We claim that this nanoflower cencept will be one of the fastest moving and most exciting research areas.

\section{Acknowledgements}

This work was supported by a grant from the Erciyes University Scientific Research Office (TSA08-590).

\section{References}

1. Horton, H.R.; Moran, L.A.; Ochs, R.S. Principles of Biochemistry. PrenticeHallInternational, Inc., New Jersey, 1996.

2. Ansari, S.A.; Husain, Q. Potential applications of enzymes immobilized on/innano materials: a review. Biotechnol. Adv. 2012, 30, 512-523.

3. Tran, D.N.; Balkus, K.J. Perspective of recent progress in immobilization ofenzymes. ACS Catal. 2011, 1,956-968.

4. Ahmad, R.; Sardar, M. Enzyme Immobilization: an overview on nanoparticlesas Immobilization matrix. Biochem. Anal. Biochem. 2015, 2, 4-2.

5. Mateo, C.; Palomo, J.M.; Fernandez-Lorente, G.; Guisan, J.M.; Fernandez-Lafuente, R. Improvement of enzyme activity: stability andselectivity via immobilization techniques. Enzyme Microbiol. Technol. 2007, 40, 1451-1463.

6. Zhang, Y.; Ge, J.; Liu, Z. Enhanced activity of immobilized or chemicallymodified enzymes. ACS Catal. 2015, 5, 4503-4513.

7. Altinkaynaka, C.; Tavlasogluc, S.; Özdemirc, N.; Ocsoy, İ. A new generation approach in enzyme immobilization: Organic-inorganic hybrid nanoflowers with enhanced catalytic activity and stability. Enzyme and Microbial Technology. 2016, 93, 105-112.

8. Kim, J.; Grate, J. W.; Wang, P. Nanobiocatalysis and its potential applications. Trends Biotechnol. 2008, 26, 639-646.

9. Luckarift, H. R.; Spain, J. C.; Naik, R. R.; Stone, M. O. Enzyme immobilization in a biomimetic silica support. Nature Biotechnol. 2004, 22, 211-213.

10. Mateo, C.; Grazu, V.; Palomo, J.M.;Lopez-Gallego, F.; Fernandez-Lafuente, R.; Guisan, J.M. Immobilization of enzymes on heterofunctional epoxy supports. Nature Protoc. 2007, 2, 1022-1027. 
11. Lei, C.; Shin, Y.; Liu, J.; Ackerman, E. J. Entrapping enzyme in a functionalized nanoporous support. J. Am. Chem. Soc. 2002, 124, 11242-11243.

12. Kim, J.; Grate, J.W.; Wang, P. Nanostructures for enzyme stabilization. Chem.Eng. Sci. 2006, 61, 1017-1026.

13. Sheldon, R.A.; Pelt, S.V. Enzyme immobilisation in biocatalysis: why, what and how. Chem. Soc. Rev. 2013, 42, 6223-6235.

14. Zaborsky, O. Enzyme reactors, in: R.C. West (Ed.), Immobilized Enzymes, CRCPress, Boca Raton, FL, 1973, 117-126.

15. Sheldon, R.A. Cross-linked enzyme aggregates $\left(\mathrm{CLEA}^{\circledR} \mathrm{s}\right)$ : stable and recyclablebiocatalysts. Biochem. Soc. Trans. 2007, 35, 1583-1587.

16. Lei, C.; Shin, Y.; Magnuson, J.K.; Fryxell, G.E.; Lasure, L.L.; Elliott, D.C.; Liu, J.; Ackerman, E.J. Characterization of functionalized nanoporous supports forprotein confinement. Nanotechnology. 2006, 17, 5531-5538.

17. Zhang, Y.; Ge, J.; Liu,Z. Enhanced activity of immobilized or chemicallymodified enzymes. ACS Catal. 2015, 5, 4503-4513.

18. Hanefeld, U.; Cao, L.; Magner, E. Enzyme immobilisation: fundamentals andapplication. Chem. Soc. Rev. 2013, 42, 15.

19. Gupta, M.; Mattiasson, B.; Enzyme function in organic solvents. Method Biochem. Anal. 1992, 1-34.

20. Cordeiro, A.L.; Lenk, T.; Werner, C. Immobilization of Bacillus licheniformis $\alpha$-amylase onto reactive polymer films. Journal of Biotechnology. 2011, 154, 216- 221.

21. Singh, V.; Kumar, P. Carboxymethyl tamarind gum-silica nanohybrids for effective immobilization of amylase. Journal of Molecular Catalysis B: Enzymatic. 2011,70, 6773.

22. Singh, S.; Saikia, J.P.; Buragohain, A.K. A novel reusable PAni-PVA-Amylase film: Activity and analysis. Colloids and Surfaces B: Biointerfaces. 2013, 106, 46- 50.

23. Li, B.; Chen, Y.;Chen, X.; Liu, D.; Niu, H.; Xiong, J.; Wu, J.;Xie,J.; Bai, J.; Ying, H. A novel immobilization method for nuclease $\mathrm{P} 1$ on macroporous absorbent resin with glutaraldehyde cross-linking and determination of its properties. Process Biochemistry. 2012, 47, 665-670.

24. Abd El-Ghaffar, M. A.; Hashem, M. S. Immobilization of a-Amylase onto Chitosan and Its Amino Acid Condensation Adducts. Journal of Applied Polymer Science. 2009, 112, 805-814.

25. Konsula, Z.; Liakopoulou-Kyriakides M. Hydrolysis of starches by the action of an $\alpha-$ amylase from Bacillus subtilis. Process Biochemistry. 2004, 39, 1745-1749.

26. Pascoal, A.M.;Mitidieri, S.; Fernandes, K.F. Immobilisation of $\alpha$-amylase from Aspergillus niger onto polyaniline. Food and bioproducts processing. 2011, 89, 300306.

27. Nwagua,T.N.; Aoyagia, H.; Okolob, B.N.; Yoshida, S. Immobilization of a saccharifying raw starch hydrolyzing enzyme on functionalized and non-functionalized sepa beads. Journal of Molecular Catalysis B: Enzymatic. 2012,78, 1-8.

28. Chen, Y.H.; Chi, M.C.; Wang, T.F.; Chen, J.C.; Lin, L.L. Preparation of Magnetic Nanoparticles and Their Use for Immobilization of C-Terminally Lysine-Tagged Bacillus sp. TS-23 $\alpha$-Amylase. Appl Biochem Biotechnol. 2012, 166,1711-1722.

29. Jiang,H.; Wang, X. Time-dependent nanogel aggregation for naked-eye assays of aamylase activity. Analyst. 2012, 137, 2582. 
30. Sahoo, B.; Sahu, S.K.; Pramanik, P. A novel method for the immobilization of urease on phosphonate grafted iron oxide nanoparticle. Journal of Molecular Catalysis B: Enzymatic. 2011, 69, 95-102.

31. Sharma, B.; Mandani, S.; Sarma, T.K. Biogenic Growth of Alloys and Core-Shell Nanostructures Using Urease as a Nanoreactor at Ambient Conditions. Scientific reports. 3, 2601, DOI: 10.1038/srep02601.

32. Pogorilyi, R. P.; Melnyk, I. V.; Zub, Y. L.; Seisenbaevab, G. A.; Kessler, V. G. Immobilization of urease on magnetic nanoparticles coated by polysiloxane layers bearing thiol- or thiol- and alkyl-functions. J. Mater. Chem. B. 2014, 2, 2694.

33. Garg, S.; De A.; Mozumdar, S. pH Dependent Immobilization of Urease on Glutathione Capped Gold Nanoparticles. Journal of Biomedical Materials Research: Part A. doi: 10.1002/jbm.a.35314.

34. Ali, A.;AlSalhi, M.S.; Atif, M.; Ansari, A.A.; Israr, M. Q.; Sadaf, J. R.; Ahmed, E.; Nur, O.; Willander, M. Potentiometric urea biosensor utilizing nanobiocomposite of chitosaniron oxide magnetic nanoparticles. Journal of Physics: Conference Series. 2013, 414, 012024 doi:10.1088/1742-6596/414/1/012024.

35. Zhou, J.; Cao, J.; Huang, W.; Huang, L.; Wang, Y.; Zhang, S.; Yuan, Y.; Hua, D. Preparation and Property of Urease Immobilization with Cationic Poly(4vinylpyridine) Functionalized Colloidal Particles. Chem. Biochem. Eng. Q. 2013, 27,4, 431-437.

36. Itabaiana, I.; Felipe, J.; Sutili, K.; Selma, G. F.; Leite, Gonçalves, K.M.; Cordeiro, Y.; Leal, I.C.R.; Miranda, Manuel L.S.M.; Ojeda, Luqued R.; de Souza, R. O. M. A. Continuous flow valorization of fatty acid waste using silica-immobilized lipases. Green Chem. 2013, 15, 518.

37. Ge, J.; Lei, J.; Zare, R. N.; Protein-inorganic hybrid nanoflowers. Nature nanotechnology. 2012,7, 7, 428.

38. Lin, Z.; Xiao, Y.; Yin, Y.; Hu, W.; Liu, W.; Yang, H. Facile synthesis of enzyme-inorganic hybrid nanoflowers and its application as a colorimetric platform for visual detection of hydrogen peroxide and phenol. ACS applied materials \& interfaces. 2014, 6, 13, 10775-10782.

39. Somturk, B.; Hancer, M.; Ocsoy, I.; Özdemir, N. Synthesis of copper ion incorporated horseradish peroxidase-based hybrid nanoflowers for enhanced catalytic activity and stability. Dalton Transactions. 2015, 44, 31, 13845-13852.

40. Ocsoy, I.; Dogru, E.; Usta, S. A new generation of flowerlike horseradish peroxides as a nanobiocatalyst for superior enzymatic activity. Enzyme and microbial technology. 2015,75, 25-29.

41. Yu, Y.; Fei, X.; Tian, J.; Xu, L.; Wang, X.; Wang, Y. Self-assembled enzyme-inorganic hybrid nanoflowers and their application to enzyme purification. Colloids and Surfaces B: Biointerfaces. 2015, 130, 299-304.

42. Yin, Y.; Xiao, Y.; Lin, G.; Xiao, Q.; Lin, Z.; Cai, Z. An enzyme-inorganic hybrid nanoflower based immobilized enzyme reactor with enhanced enzymatic activity. Journal of Materials Chemistry B. 2015, 3, 11, 2295-2300.

43. Batule, B. S.; Park, K. S.; Kim, M. I.; Park, H. G. Ultrafast sonochemical synthesis of protein-inorganic nanoflowers. International journal of nanomedicine. 2015, 10(Spec Iss), 137. 
44. Somturk, B.; Yilmaz, I.; Altinkaynak, C.; Karatepe, A.; Özdemir, N.; Ocsoy, I. Synthesis of urease hybrid nanoflowers and their enhanced catalytic properties. Enzyme and microbial technology. 2016, 86, 134-142.

45. Altinkaynak, C.; Yilmaz, I.; Koksal, Z.; Özdemir, H.; Ocsoy, I.; Özdemir, N. Preparation of lactoperoxidase incorporated hybrid nanoflower and its excellent activity and stability. International journal of biological macromolecules. 2016, 84, 402-409.

46. Ke, C.; Fan, Y.; Chen, Y.; Xu, L.; Yan, Y. A new lipase-inorganic hybrid nanoflower with enhanced enzyme activity. RSC Advances. 2016, 6,23, 19413-19416.

47. Altinkaynak, C.; Tavlasoglu, S.; Kalin, R.; Sadeghian, N.; Ozdemir, H.; Ocsoy, I.; Özdemir, N. A hierarchical assembly of flower-like hybrid Turkish black radish peroxidase-Cu2+ nanobiocatalyst and its effective use in dye decolorization. Chemosphere. 2017, 182, 122-128.

48. Li, H.; Hou, J.; Duan, L.; Ji, C.; Zhang, Y.; Chen, V. Graphene oxide-enzyme hybrid nanoflowers for efficient water soluble dye removal. Journal of hazardous Materials. 2017, 338, 93-101.

49. Lee, D. C.; Smith, D. K.; Heitsch, A. T.; Korgel, B. A. Annu. Rep. Prog. Chem., Sect. C: Phys. Chem. 2007, 103, 351-402.

50. Ocsoy, I.; Gulbakan, B.; Shukoor, M.I.; Xiong, X.; Chen, T.; Powell, D.H.; Weihong, Tan. Aptamer-Conjugated Multifunctional Nanoflowers as a Platform for Targeting, Capture, and Detection in Laser Desorption Ionization Mass Spectrometry. ACS Nano. 2013, 7,1, 417-427.

51. Sun, J.; Ge, J.; Liu, W.; Lan, M.; Zhang, H.; Wang, P.; Niu, Z. Multi-enzyme coembedded organic-inorganic hybrid nanoflowers: synthesis and application as a colorimetric sensor. Nanoscale. 2014, 6,1, 255-262.

52. Zhu, X.; Huang, J.; Liu, J.; Zhang, H.; Jiang, J.; Yu, R. A dual enzyme-inorganic hybrid nanoflower incorporated microfluidic paper-based analytic device ( $\mu P A D)$ biosensor for sensitive visualized detection of glucose. Nanoscale. 2017, 9,17, 5658-5663.

53. Ye, R.; Zhu, C.; Song, Y.; Song, J.; Fu, S.; Lu, Q.; Lin, Y. One-pot bioinspired synthesis of all-inclusive protein-protein nanoflowers for point-of-care bioassay: detection of E. coli 0157: H7 from milk. Nanoscale. 2016, 8(45), 18980-18986.

54. Ye, R.; Zhu, C.; Song, Y.; Lu, Q.; Ge, X.; Yang, X.; Lin, Y. Bioinspired Synthesis of All-inOne Organic-Inorganic Hybrid Nanoflowers Combined with a Handheld pH Meter for On-Site Detection of Food Pathogen. Small. 2016, 12(23), 3094-3100.

55. Liu, Y., Chen, J., Du, M., Wang, X., Ji, X., \& He, Z. The preparation of dual-functional hybrid nanoflower and its application in the ultrasensitive detection of diseaserelated biomarker. Biosensors and Bioelectronics. 2017, 92, 68-73.

56. Wu, Z-F., Wang Z., Zhang, Y., Ma, Y-L., He, C-Y, Li, H., Chen, L., Huo, Q-S., Wang, L., Li, $Z-Q$. Amino acids-incorporated nanoflowers with an intrinsic peroxidase-like activity. Scientific Reports, 2016, 6, 22412.

57. Ildiz, N., Baldemir, A., Altinkaynak, C., Özdemir, N., Yilmaz, V., Ocsoy, I. Self assembled snowball-like hybrid nanostructures comprising Viburnum opulus L. extract and metal ions for antimicrobial and catalytic applications Enzyme and Microbial Technology 102 (2017) 60-66

58. Baldemir, A., Kose, n. B., Ildız, N., Ilgun, S., Yusufbeyoglu, S., Yilmaz V., and Ocsoy, I. Synthesis and characterization of green tea (Camellia sinensis (L.) Kuntze) extract and its major components-based nanoflowers: a new strategy to enhance antimicrobial activity. RSC Advances. 2017, 7, 44303. 
59. Baldemir, A., Karaman, Ü., Yusufbeyoğlu, S., Eken, A., Ildız, N., İlgün, S., Çolak, C., Kaçmaz, G., Öçsoy, İ., Çankaya, S. Laurocerausus officinalis Roemer (Taflan) Meyve Ekstrelerinden Nanoçiçek Sentezi ile Akantamoebisidal Aktivitenin Arttırılmasında Yeni Bir Strateji. Mikrobiyoloji Bülteni. 2018, 52, 56-71.

Duman F, Ocsoy I, Kup F-O (2016) Chamomile flower extract-directed CuO nanoparticle formation for its antioxidant and DNA cleavage properties. Mat Sci Eng C 60:333-338 Demirbas A, Welt B-A, Ocsoy I (2016) Biosynthesis of red cabbage extract directed Ag NPs and their effect on the loss of antioxidant activity. Mater Lett 179:20-23

Karatoprak G-Ş, Aydin G, Altinsoy B, Altinkaynak C, Koşar M, Ocsoy I (2017) The effect of pelargonium Endlicherianum fenzl. Root extracts on formation of nanoparticles and their antimicrobial activities. Enzyme Microb Technol 97:21-26

Ocsoy I, Temiz M, Celik C, Altinsoy B, Yilmaz V, Duman F (2017) A green approach for formation of silver nanoparticles on magnetic graphene 